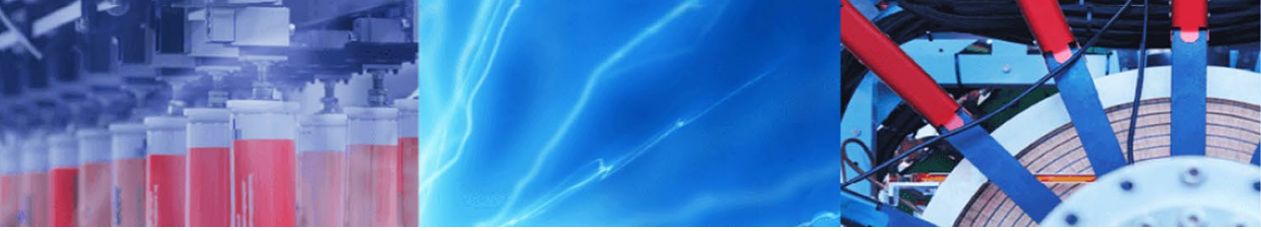

Research Article

\title{
Surface modification of structural material for nuclear applications by electron beam melting: enhancement of microstructural and corrosion properties of Inconel 617
}

\author{
Soumyabrata Basak ${ }^{1,2}$ - Sumit K. Sharma ${ }^{3} \cdot$ Kisor K. Sahu² $^{2}$ Srikant Gollapudi ${ }^{2}$. Jyotsna Dutta Majumdar ${ }^{3}$
}

(c) Springer Nature Switzerland AG 2019

\begin{abstract}
Inconel 617 is widely used in nuclear industry, due to its excellent elevated temperature mechanical and chemical properties. In this study, austenitic super alloy Inconel 617 has been subjected to electron beam surface melting using an indigenously developed electron beam welding unit $(80 \mathrm{kV}, 12 \mathrm{~kW})$ for microstructural homogenization and understanding its effect on corrosion resistance property. Electron beam surface melting has been carried out at a gun voltage of $60 \mathrm{kV}$, current of $30 \mathrm{~mA}$, and scan speed of $1000 \mathrm{~mm} / \mathrm{min}$ inside a vacuum chamber with a vacuum level of $1.6 \times 10^{-5} \mathrm{mb}$. Surface melting induced by EBM led to development of refined microstructural features consisting of $\gamma$ dendrites and precipitates of $\mathrm{Ni}_{3}(\mathrm{Al}, \mathrm{Ti})$ in the interdendritic regions, which further improved microhardness of the Electron Beam (EB) treated surface. The effect of electron beam melting on the kinetics of aqueous corrosion has been determined in acidic $3.56 \mathrm{wt} \% \mathrm{NaCl}$ media. The improvement in corrosion resistance can be attributed to the microstructural refinement leading towards the redistribution and homogenization of alloying elements and surface purification.
\end{abstract}

Keywords Electron beam melting · Inconel $617 \cdot$ Nuclear energy $\cdot$ Potentiodynamic polarization $\cdot$ Corrosion

\section{Introduction}

Excellent high temperature oxidation resistance, corrosion resistance, and high temperature phase stability make solid solution strengthened nickel-base superalloy more popular as a next generation candidate structural material in nuclear reactors such as Pressurized Water Reactors (PWR) and Very High Temperature Reactor (VHTR) [1-5]. Inconel 617 is a class of $\mathrm{Ni}$ based superalloy with the following major alloying elements: Chromium, Molybdenum, Titanium, Cobalt, Aluminum, Iron, Cooper etc. Addition of chromium, and molybdenum is responsible for the higher corrosion and oxidation resistance, whereas, presence of higher amount of nickel with combination of cobalt imparts high ductility, with the desired mechanical strength for this specific application [3,5]. However, under severe service conditions, defects occur on the surface of these materials due to the simultaneous presence of stresses (residual, tensile, or both), high pressure, presence of highly aggressive environment and erosion [6-8]. This problem can be overcome by tailoring the surface microstructure and/or composition without altering the fundamental bulk properties of the substrate materials [8]. Surface modification processes have been employed to minimize corrosion, reduce frictional energy losses, increase fatigue life, improve wear resistance, and enhance chemical stability at high temperature and for decorative purpose $[9,10]$. Among the different surface engineering techniques, laser surface melting was reported to improve hardness and corrosion resistance of a few structural

$\triangle$ Soumyabrata Basak, sb34@iitbbs.ac.in|'School of Engineering and Technology, Adamas University, Kolkata, West Bengal 700126, India. ${ }^{2}$ School of Minerals, Metallurgical and Materials Engineering, Indian Institute of Technology Bhubaneswar, Argul campus, Jatani, Odisha 752050, India. ${ }^{3}$ Department of Metallurgical and Materials Engineering, Indian Institute of Technology Kharagpur, Kharagpur, West Bengal 721302, India.

SN Applied Sciences (2019) 1:708 | https://doi.org/10.1007/s42452-019-0744-5

Received: 26 February 2019 / Accepted: 5 June 2019 / Published online: 11 June 2019 
materials in simulated nuclear environments [10-12]. In quest for higher energy efficiency, electron beam surface melting has been found to be more attractive than the laser beams or other additive manufacturing techniques, pertaining to applications in nuclear, bio-medical, automobile and aerospace industries due to the formation of contamination free surface [13]. Several studies had reported the positive impact of electron beam processing on surface mechanical properties of several structural materials like Inconel 625 and Inconel 718 due to microstructural refinement and homogenization [14-16]. However, no literary evidence is available detailing on the specific microstructural changes related to the effect of electron beam melting of Inconel 617 superalloy on its corrosion resistance property. This is a critically important piece of information for a material to be deployed in highly aggressive nuclear environments. In the present study, a detailed investigation of the effect of electron beam surface melting on the microstructures, surface mechanical and electro-chemical properties of Inconel 617 have been undertaken.

\section{Materials and experimental procedures}

\subsection{Test materials}

In this study, commercially pure nickel based austenitic super alloy (Inconel 617) has been chosen as the substrate material. Material was then solution annealed at $1120^{\circ} \mathrm{C}$ $\left(2048^{\circ} \mathrm{F}\right.$ ) for $30 \mathrm{~min}$ followed by oil quenching prior to the machining of the test specimens. The chemical composition of these materials is given in Table 1.

\subsection{Experimental procedures}

In the present study, rectangular shaped Inconel 617 with the dimensions of $50 \mathrm{~mm} \times 25 \mathrm{~mm} \times 5 \mathrm{~mm}$ was machined from heat treated material and was used as substrate. The substrates were carefully ground using belt grinder of roughness value $25 \mu \mathrm{m}$ and cleaned with ethanol and acetone prior to melting. An indigenously developed electron beam welding machine with a maximum accelerated voltage of $80 \mathrm{kV}$ was used for melting of Ni-based Austenitic super alloy, Inconel 617. Surface melting was carried out at an accelerated voltage of $40 \mathrm{kV}$, current of $30 \mathrm{~mA}$ and scan speed of $1000 \mathrm{~mm} / \mathrm{min}$ inside a vacuum chamber $\left(1.6 \times 10^{-5} \mathrm{mb}\right)$. Followed by melting, the samples were cut into rectangular shape of dimensions $10 \mathrm{~mm} \times 10 \mathrm{~mm} \times 5 \mathrm{~mm}$ and further mechanically polished with proper care. For the microstructural observation, samples were etched using acidic Aqua Regia (a mixture of nitric acid and hydrochloric acid in a molar ratio of 1:3). Light microscope (LEICA DMI3000 M) was employed to investigate the surface microstructure at low magnification. Surface roughness evaluation of both pre-and postelectron beam melted (EBM) region was performed by using a 3D non-contact optical profilometer (New view NV $600, M / S$ Zygo Corporation, USA). Cross sectional region of this melted specimen was mechanically polished and etched for the microstructural observations on both the substrate and electron beam melted zones by the optical and scanning electron microscopes respectively (LEICA DMI3000 M and ZEISS GEMINI SEM 500). A detailed investigation of the phases at both substrate and electron beam melted region were carried out by X-ray diffraction (XRD) technique (D8 Advances, Bruker AXS, Germany). Microhardness of both these regions was measured using a load of $50 \mathrm{gf}$ applied for $10 \mathrm{~s}$. Finally, the top surface of the melted samples was thoroughly ground and polished for corrosion test and analysis in aqueous medium. Before that the samples were rinsed with acetone to remove any dirt on the surface, and except the reaction area, entire sample was coated by a polymeric film to prevent reaction with the electrolyte. The electrochemical characterization was carried out by potentio-dynamic polarization test using a PS6 Meinsberger Potentiostat/Galvanostat connected to a standard three electrode cell comprising the sample as the working electrode, a saturated calomel reference electrode and a platinum counter electrode. The electrolyte used was acidic $3.5 \mathrm{wt} \% \mathrm{NaCl}$ solution (3.5 Wt\% $\mathrm{NaCl}+$ Acetic acid, pH 3.15).

\section{Results and discussion}

\subsection{Characterization of the melt zone}

Presence of defects like porosity, gas holes, and pin holes are observed in small quantity inside the melt zone of
Table 1 Chemical composition of Inconel 617 (wt\%) used in the present study

\begin{tabular}{llllllllllllllll}
\hline Mat. & $\mathrm{C}$ & $\mathrm{Mn}$ & $\mathrm{P}$ & $\mathrm{S}$ & $\mathrm{Si}$ & $\mathrm{Ni}$ & $\mathrm{Cr}$ & $\mathrm{Mo}$ & $\mathrm{Co}$ & $\mathrm{Al}$ & $\mathrm{B}$ & $\mathrm{Cu}$ & $\mathrm{Ti}$ & $\mathrm{Fe}$ \\
\hline Inconel 617 & 0.08 & 0.37 & 0.003 & 0.004 & 0.35 & 55.12 & 20.68 & 8.18 & 10.89 & 0.94 & 0.003 & 0.16 & 0.24 & 2.98
\end{tabular}


electron beam melted surface due to the presence of dissolved gas, local evaporation of material because of high temperature and presence of low melting point species (Al) in trace quantity in addition to the presence of high surface tension associated with a large thermal gradient [17].

Once, the intrinsic gas bubbles are generated due to processing in vacuum, it is impossible to eliminate them from electron beam melted zone, leading to the formation of gas holes [18]. In the present study, it was however, observed that optimization of process parameters leads to formation of defect free melt zone. Figure 1 shows the optical microstructure of the top surface of melted Inconel 617 at various magnifications, where, no such visible defects are observed in the aforesaid melt processing conditions. Due to the surface tension gradient arising by a large thermal gradient, ripple formation on the surface is a commonly observed phenomenon which causes roughening of the surface. The average surface roughness (Ra) of the melt zone was found to be increased to a little extent $(13.5 \mu \mathrm{m})$ as compared to as-received substrate $(12.2 \mu \mathrm{m})$. From the negligible difference in surface roughness between electron beam melted surface and as-received substrate, it may be concluded that the electron beam melting operation using the present set of parameters may be applied on finished component. Figure $2 a$ and $b$ show the 3-dimensional surface roughness profile of (a) as-received and (b) electron beam surface melted Inconel 617 derived from the optical profilometer. A detailed comparison between Fig. $2 a$ and $b$ shows that the surface waviness decreases in the melt zone as compared to asreceived sample, the average surface roughness value does not vary significantly.

The decreased waviness of the surface due to electron beam melting is attributed to uniform melting of the surface region and its spreading causing micro-smoothening of the surface.

Figure 3 shows the optical micrograph of as-received Inconel 617 used in the present study as substrate. This micrograph reveals the presence of austenitic grains with the annealing twins [19]. The grain size distribution is bimodal in nature which is evident from the presence of both the fine and coarse austenitic grains throughout the microstructures due to the solution annealing operation done on the materials during the heat treatment $[20,21]$. The heat-treated alloy shows a very little and fine dispersion of precipitated particles in a matrix of a deformable metal. The precipitated particles act as barriers to dislocation motion, thus causing strengthening of the heattreated alloys [19-22].

Figures $4 a-c$ show the light micrographs of the (a) cross section of electron beam melted Inconel 617 and high magnification view of (b) zone 1 and (c) zone 2. From Fig. $4 a$ it is evident that the melted region is separated from the substrate with a solid-liquid interface boundary. The melt zone consists of the presence of columnar dendritic structure [7, 23-25]. This microstructural change occurs during the electron beam melting due to the rapid solidification rate (RSS) inside the melting pole, which resulted in micro segregation, and grain size reduction along with decreasing number of grain boundaries, and a higher amount of strength and hardness of the structural materials in those conditions as compared to as-received substrate [15]. The microstructure of the melt zone near to the solid-liquid interface (cf. Figure 4c) consists of very fine columnar dendritic morphology with a very low secondary dendritic spacings. The columnar dendritic structure changes to dendrites away from the interface. Directional solidification occurs with the formation of columnar grains, which are followed by the formation of the tree
Fig. 1 Optical micrographs of the top surface of electron beam surface melted Inconel 617 showing the a melt track at low magnification, b Magnified view inside the melt track
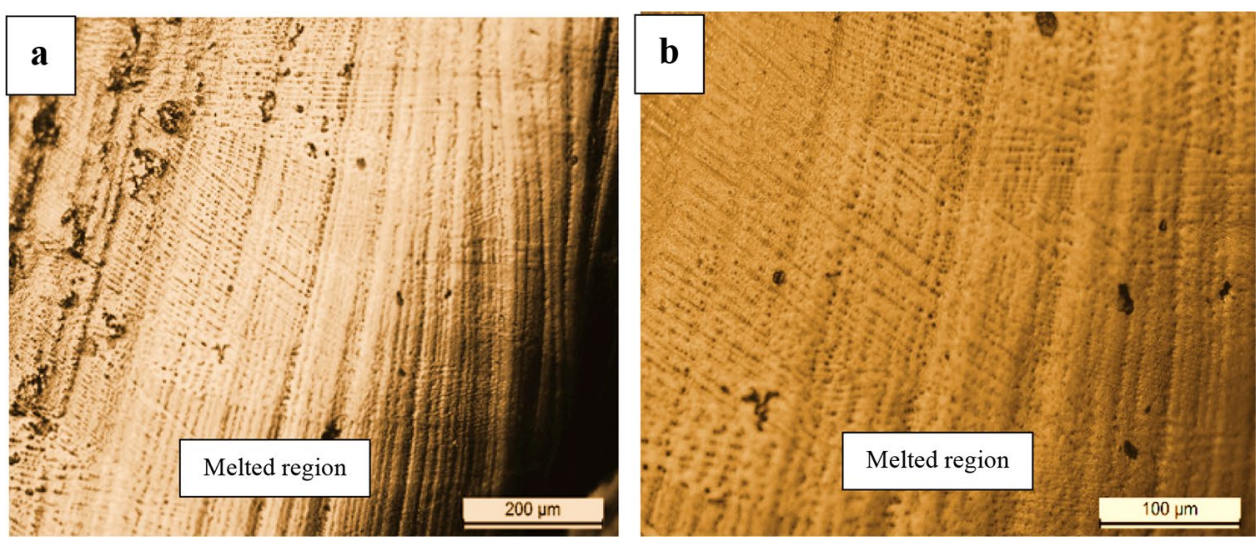

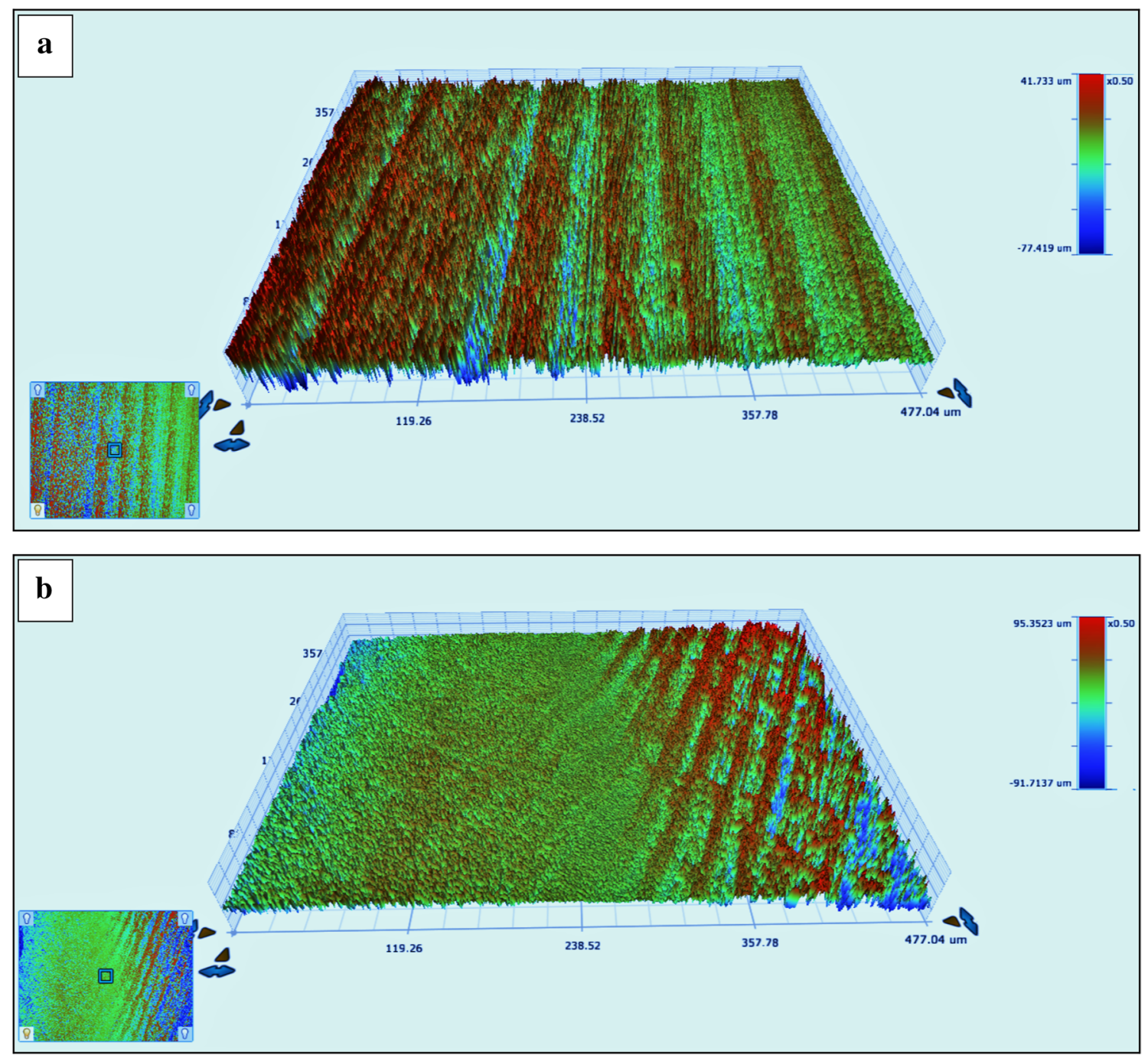

Fig. 2 3-D surface topography of $\mathbf{a}$ as-received and $\mathbf{b}$ electron beam surface melted Inconel 617

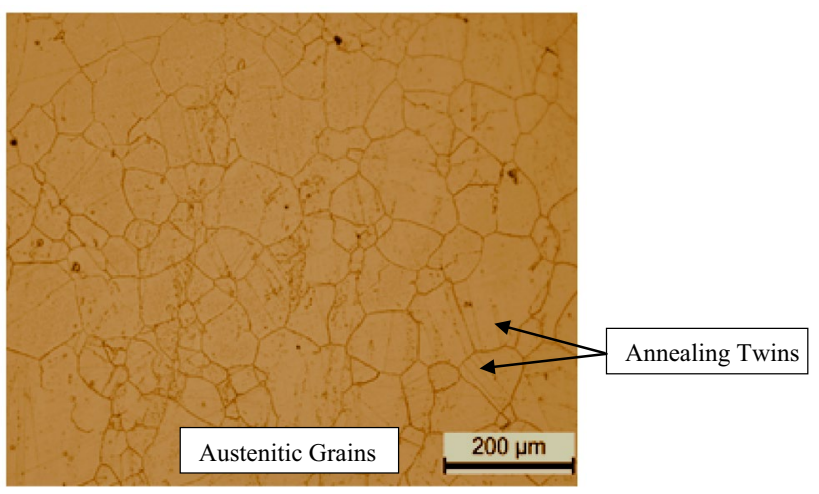

Fig. 3 Optical micrograph of the as-received Inconel 617 used in the present study shape dendritic microstructures, which have a pronounced effect on the corrosion behavior $[15,26]$. Coarsening of the grains have a resilient impact on the corrosion resistance of the structural materials due to reduced number of defects, plastic deformation and segregated impurities $[27,28]$. Grains are oriented in the melt zone in various directions due to the presence of larger number of nucleation sites inside the melted region which varies from materials to materials $[15,29,30]$. From the development of the dendritic arm spacing, it is understood that the constitutional super cooling in the intervening liquid metal zone is reduced at a very low level $[16,29]$. It has been reported that the microstructure is columnar and dendritic throughout the melted zone of electron beam melted Inconel 617 

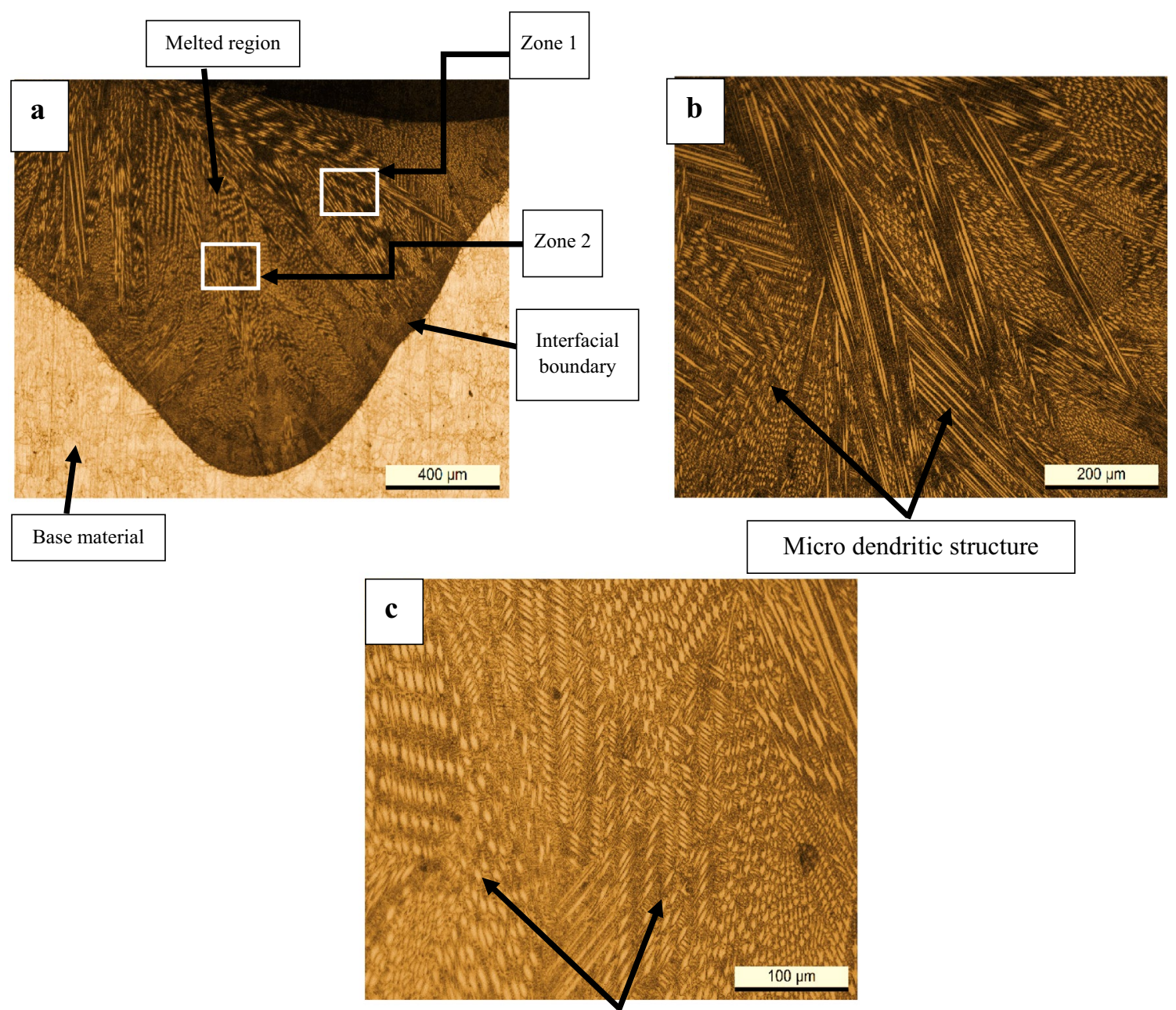

Columnar Architecture

Fig. 4 Optical micrographs of the a cross-section of electron beam melted Inconel 617 and $\mathbf{b}$, $\mathbf{c}$ the same at high magnifications from zone 1 and zone 2 respectively

Fig. 5 Scanning electron micrographs of the cross-section of electron beam melted Inconel 617 showing a interfacial region and $\mathbf{b}$ top surface
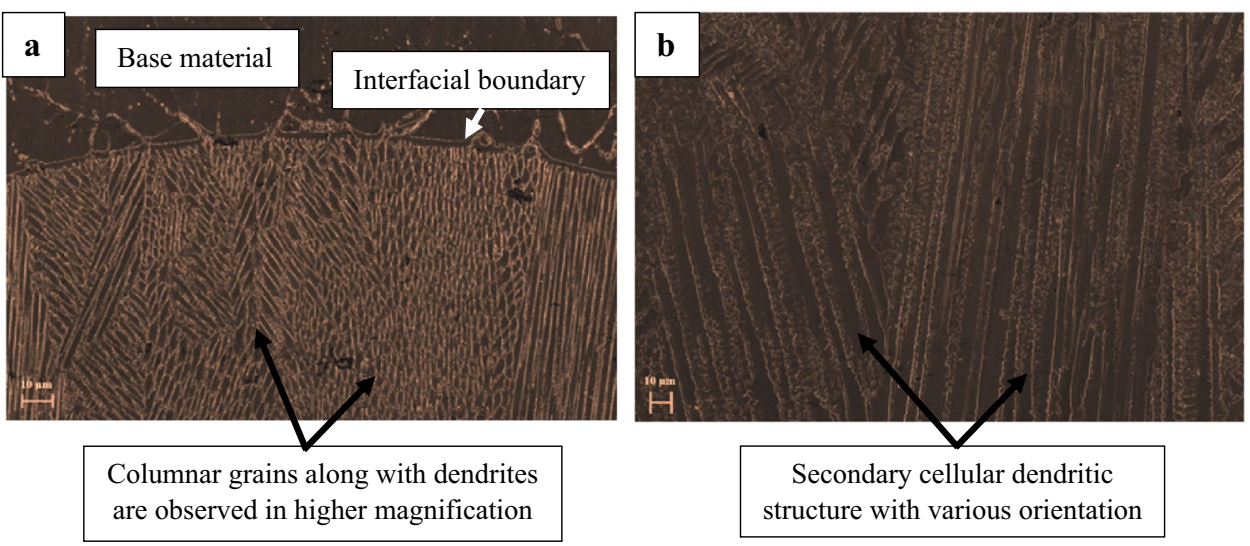


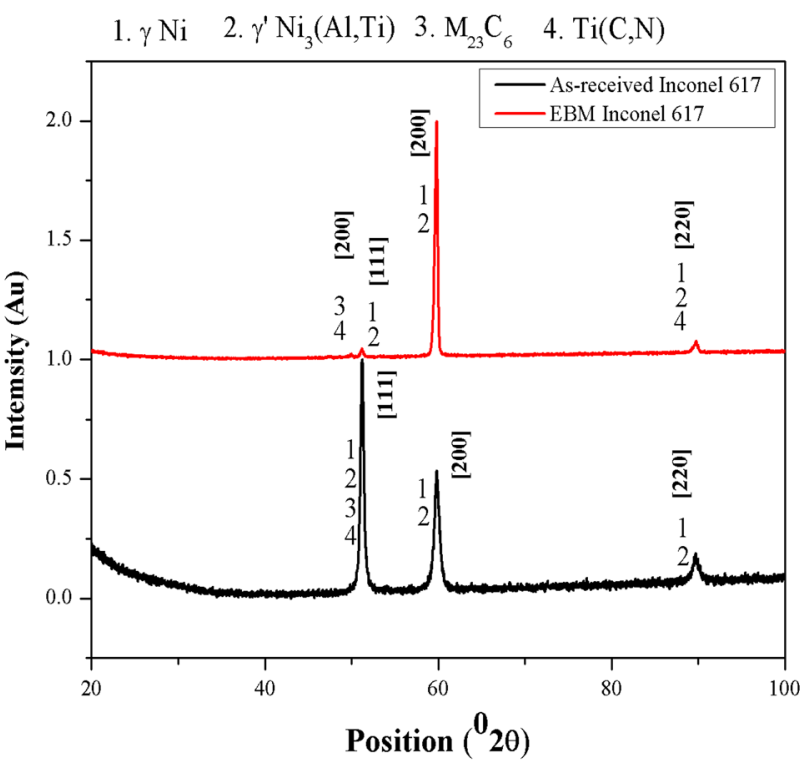

Fig. 6 X-ray diffraction patterns of the top surface of as-received and electron beam surface melted Inconel 617

[15, 27-29]. Such microstructural changes offer adequate improvement of mechanical properties as well as the corrosion resistance of the structural materials.

For the detailed investigation of the microstructure of the electron beam melted Inconel 617, the microstructures of the solid liquid interface have been analyzed in detail. Figure 5 a shows the scanning electron micrograph of the solid-liquid interface as an evidence of the presence of defect free interface. The high magnification view of the near interface microstructure in Fig. $5 \mathrm{~b}$ shows that the columnar grains are oriented in different directions. In addition, there is presence of very fine grains growing from the main column like dendrites but for a very short distance and without the presence of any secondary arms.

A detailed X-ray diffraction analysis of the as-received and electron beam melted Inconel 617 (cf. Figure 6) shows the presence of carbide and carbonitride along with the gamma and gamma prime $\left(\gamma / \gamma^{\prime}\right)\left[\left(\mathrm{Ni}^{\prime} / \mathrm{Ni}_{3}(\mathrm{AlTi})\right)\right]$ phases. A significant narrowing of the gamma and gamma prime $\left(\gamma / \gamma^{\prime}\right)$ phases was also noticed in the X-ray diffraction profile possibly because of a large residual micro-stress introduced in the structure [31,32]. Average lattice strain developed in the material was calculated from the analysis of peak broadening using Scherer's formula [33]. In addition to different mass fraction of individual mass constituent, there is also a visible change in the texture. A detailed inspection of the lattice strain, relative intensity and texture coefficient introduced in the Inconel 617 at both pre and post EBM conditions are summarized in Table 2 .

From Table 2 it is noted that lattice strain is reduced due to surface melting as compared to as-received substrate. The reduction in lattice strain is attributed to solutionization of $\gamma^{\prime}$ precipitates after electron beam melting, due to slow cooling associated with this processing. The increase in relative intensity $\left(1 / I_{0}\right)$ of $\gamma / \gamma^{\prime}$ peaks from 48.42 for as-received Inconel 617 to 100 for electron beam melted Inconel 617 further corroborates that $\gamma^{\prime}$ content is diminished due to electron beam melting. The texture coefficient along (111) plane is also found to increase to 0.92986218 for electron beam melted Inconel 617 from 0.631502681 for as-received one.

From the texture coefficient change, it may be concluded that there is preferred texturing along (111) plane due to electron beam melting of Inconel 617 [34, 35].

\subsection{Properties of the melt zone}

A detailed evaluation of mechanical (surface micro-hardness) and electrochemical (aqueous corrosion resistance)

Table 3 Summary of microhardness of as-received and electron beam surface melted Inconel 617

\begin{tabular}{llll}
\hline Materials & $\begin{array}{l}\text { Average micro } \\
\text { hardness at pre- } \\
\text { EBM condition }\end{array}$ & $\begin{array}{l}\text { Average micro } \\
\text { hardness at post- } \\
\text { EBM condition }\end{array}$ & Differences \\
\hline Inconel 617 & $243 \pm 4.9 \mathrm{VHN}$ & $315 \pm 4.2 \mathrm{VHN}$ & 72 \\
\hline
\end{tabular}

Table 2 Summary of the lattice strain, relative intensity and texture coefficient of $\gamma$ phase in as-received and electron beam surface melted Inconel 617

\begin{tabular}{llll}
\hline Sample ID & Lattice strain & $\begin{array}{l}\text { Relative intensity }\left(\mathrm{I} / \mathrm{I}_{0}\right) \text { of } \\
\gamma / \gamma^{\prime} \text { at } \theta=59.80^{\circ}\end{array}$ & $\begin{array}{l}\text { Texture coef- } \\
\text { ficient (along } 111 \\
\text { plane) }\end{array}$ \\
\hline As-received Inconel 617 & $0.39 \pm 0.07$ & $48.43 \pm 0.002$ & $0.63 \pm 0.002$ \\
EBM Inconel 617 & $0.32 \pm 0.06$ & $100 \pm 0$ & $0.93 \pm 0.001$ \\
\hline
\end{tabular}




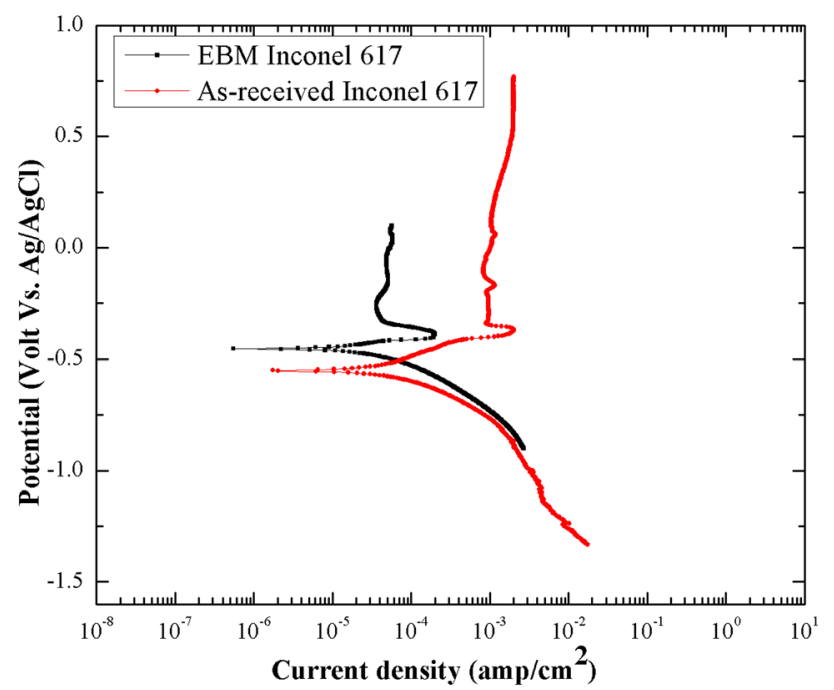

Fig. 7 Potentiodynamic polarization behavior of as-received (red color) and electron beam surface melted Inconel 617 (black color) in a $3.56 \mathrm{wt} \%$ acidic $\mathrm{NaCl}$ Solution $(\mathrm{pH} 3.15)$

properties of the melt zone was carried out to understand the effect of surface melting on the properties of the surface. The average microhardness of the as-received and electron beam melted Inconel 617 are summarized in Table 3.

From Table 3 it may be noted that there is a marginal improvement in the microhardness value due to electron beam melting. The increase in microhardness of the Electron Beam (EB) treated surface is higher on account of the fine microstructural features. As the microstructure of the EB treated surface reveals, it has a dendritic microstructure with a distribution of two distinct phases [13, 36]. The hardness of the EB treated surface is expected to be controlled by the mean free length available for dislocations travelling within either of the two phases. It is well known in eutectic microstructures that the interlamellar spacing controls the strength and hardness of the material, with finer interlamellar spacing based materials bearing higher hardness and strength compared to others. This is on account of the increase in the geometrical obstacles to the dislocation motion presented by the lamellar boundaries to dislocation [37, 38]. In our work, we believe the improvement in hardness of the EB treated surface is due to the low mean free length available for dislocation motion and this is on account of the fine microstructural features. On account of the complexity of the microstructure, evident from the Figs. $4 b$ and $5 a$, it is difficult to attribute a single microstructural length value to describe the microstructure. However, if one takes a look at the microstructures in Fig. $5 \mathrm{a}$ and $\mathrm{b}$, the spacing between the white phases is on the order of 2-5 $\mu \mathrm{m}$ and this can be chosen as an approximate representative of the mean free length for dislocation motion. Clearly this value is significantly lower than the grain size of the asreceived Inconel 617 and thus causes an increase in the hardness of the material.

The corrosion resistance property of as-received and electron beam melted Inconel 617 was evaluated in $3.56 \mathrm{wt} \% \mathrm{NaCl}$ solution (acidic) using potentiodynamic polarization technique. Figure 7 shows the potentiodynamic polarization plots of as-received and EB melted Inconel 617 in an acidic 3.56 wt $\% \mathrm{NaCl}$ solution. The CPP diagram represents an active-passive behavior in both asreceived and EB melted specimen.

The summary of corrosion parameters in terms of corrosion potential $\left(\mathrm{E}_{\text {corr }}\right)$, pitting potential $\left(\mathrm{E}_{\text {pit }}\right)$ and corrosion rate obtained from the CPP diagram, are summarized in Table 4. An evaluation of these data indicate that $E_{\text {corr }}$ of the electron beam melted surface shifts towards noble direction as compared to as-received substrate. As $E_{\text {corr }}$ is the potential at which rate anodic dissolution is equal to the rate of cathodic reduction, the increase of its magnitude indicates lower susceptibility to corrosion of the electron beam melted surface [39].

The improvement in corrosion resistance can be attributed to the refinement of the microstructure. Ralston and Birbilis have conducted an exhaustive review of the effect of grain size on corrosion resistance of materials. Based on their review, Ralston and Birbilis concluded that grain

Table 4 Summary of the corrosion parameters derived from potentiodynamic polarization study of as-received and electron beam surface melted Inconel 617

\begin{tabular}{lllll}
\hline Materials & $\mathrm{I}_{\text {corr }}\left(\mathrm{A} / \mathrm{cm}^{2}\right)$ & $\mathrm{E}_{\text {corr. }}(\mathrm{V})$ & $\mathrm{E}_{\text {pit. }}(\mathrm{V})$ & Corrosion rate $(\mathrm{mm} /$ year $)$ \\
\hline EBM Inconel 617 & $(7.0 \pm 0.001) \times 10^{-6}$ & $-0.45 \pm 0.001$ & $(4.0 \pm 0.001) \times 10^{-1}$ & $(8.0 \pm 0.002) \times 10^{-2}$ \\
As-received Inconel 617 & $(2.5 \pm 0.002) \times 10^{-5}$ & $-0.55 \pm 0.002$ & $(3.8 \pm 0.001) \times 10^{-1}$ & $(2.9 \pm 0.001) \times 10^{-1}$ \\
\hline
\end{tabular}



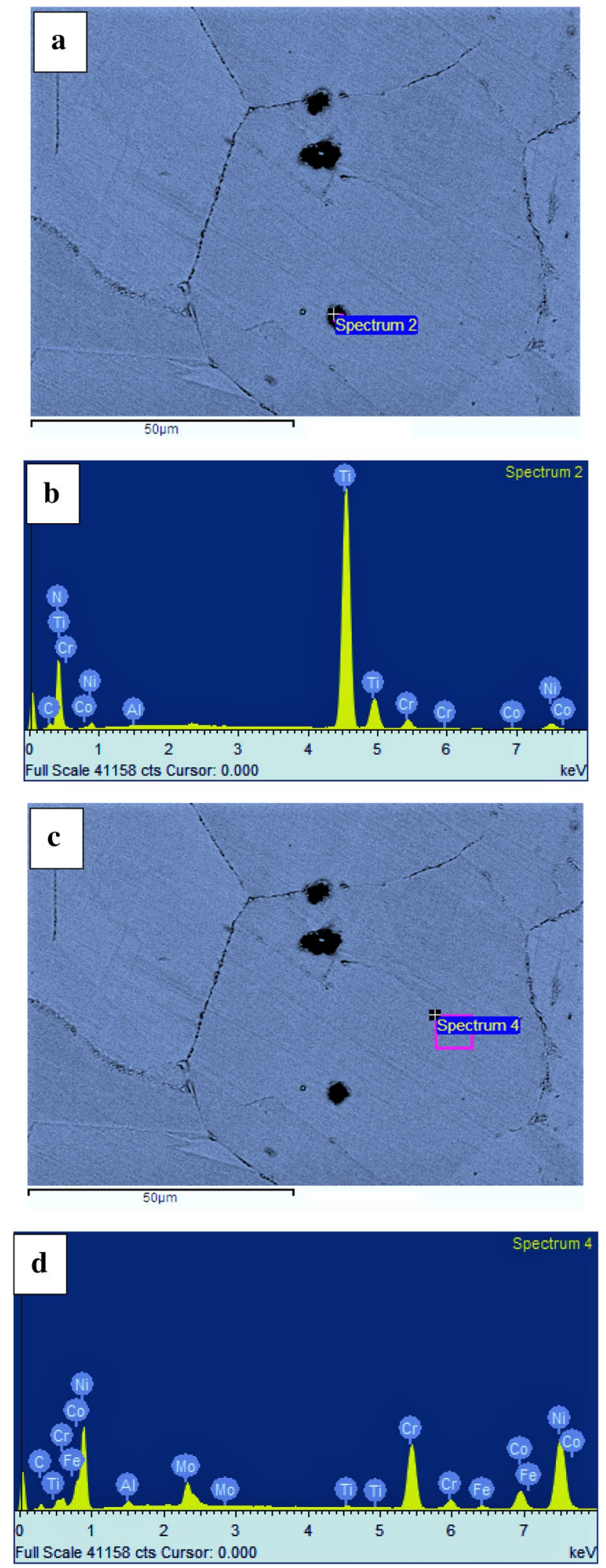

Fig. 8 Spot Energy Dispersive X-Ray Spectroscopy (EDS) analysis on asreceived Inconel 617 a, b spot on precipitates and its corresponding EDS pattern, $\mathbf{c}, \mathbf{d}$ spot on matrix and its corresponding pattern refinement leads to improvement in corrosion resistance in passivating environments and a converse of the same is observed in corroding environments [40]. Thus fine grained microstructures are more resistant to corrosion in passivating environments [40,41]. In the present study, we clearly observe an improvement in corrosion performance following electron beam treatment. The passivating current density i.e. I pass for EB treated Inconel 617 at $4.5 \times 10^{-5} \mathrm{~A} / \mathrm{cm}^{2}$ is lower compared to that of the as-received Inconel 617 at $10^{-3} \mathrm{~A} / \mathrm{cm}^{2}$. The lowering of the passivation current density is clearly indicating the improved passivation tendency of the EB treated material. While we suspect surface purification after high energy electron beam irradiation due to selective ablation for commonly observed impurities in the base material, we believe microstructural refinement to have a greater bearing on the corrosion performance [42, 43]. Furthermore, it also possible that EB melting is leading to redistribution and homogenization of alloying elements which in turn could reduce the galvanic coupling tendency of the alloying elements with respect to the matrix. Indeed electrochemical studies on $1050 \mathrm{Al}$ alloys following equal channel angular processing have demonstrated improvement in corrosion performance. The improvement in corrosion performance following ECAP was attributed to a refinement of size of the silicon containing impurities which were creating micro-galvanic couples between the Al matrix and silicon containing mixed oxide [44]. Since it is well known that galvanic corrosion is higher when the ratio of the area of the cathode to anode is high, size refinement of the cathodic precipitates following ECAP leads to a reduction of galvanic corrosion. In the current case, an evaluation of the distribution of elements before and after EB treatment reveals very interesting results [44, 45].

In continuation, the as-received Inconel 617 has been found to have a distribution of precipitates as shown in Fig. 8. These precipitates appear to be primarily TiN based precipitates as evident from the spot Energy Dispersive X-Ray Spectroscopy (EDS) analysis. The spot EDS pattern taken from the matrix shows that it is rich in nickel and chromium unlike the precipitates which are rich in titanium and nitrogen.

The elemental maps obtained from the as received Inconel 617 as shown in Fig. 9 provides further evidence for the chemical composition of the precipitates. The precipitates clearly overlap with the elemental map of titanium indicating that these are titanium rich precipitates. These precipitates thus can bear a tendency to create micro-galvanic couples with the matrix which is nickel and chromium rich.

It is interesting to note that following EB treatment, the number of these precipitates have come down as shown in

\section{SN Applied Sciences}




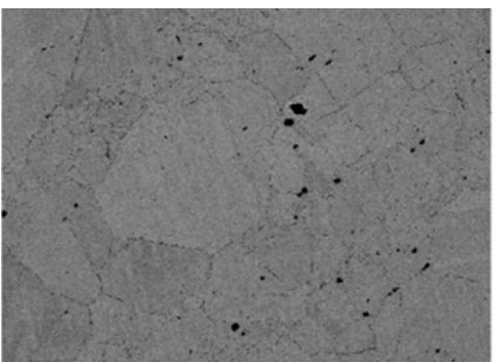

Electron Image 1

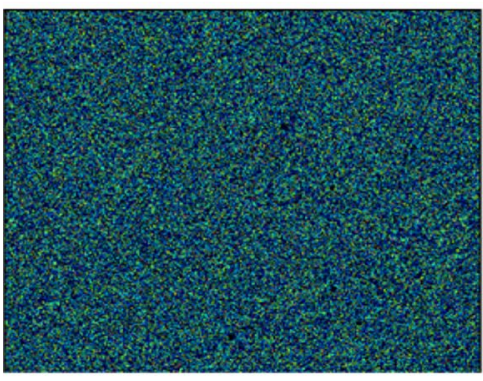

$\mathrm{Cr} \mathrm{Ka} 1$

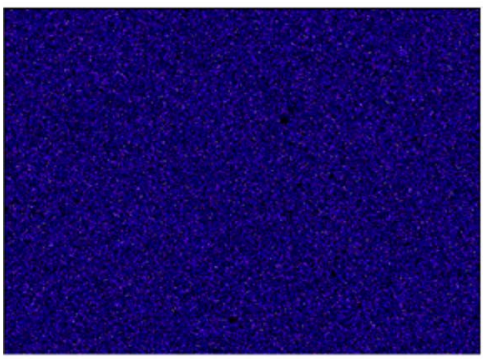

Ni Ka1

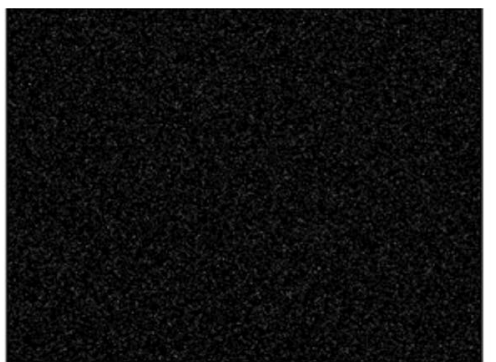

Al Ka1

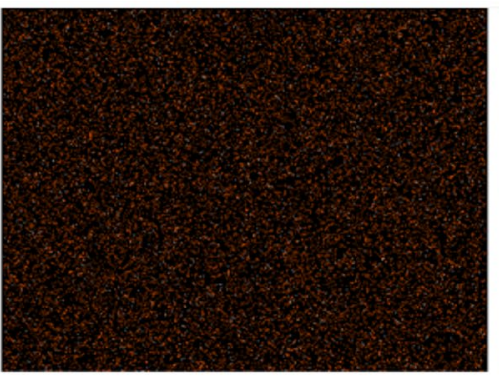

Fe Ka1

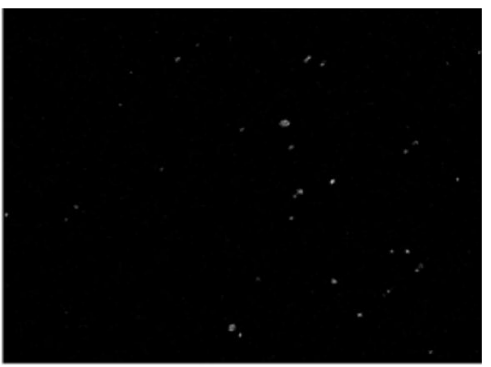

Ti Ka1

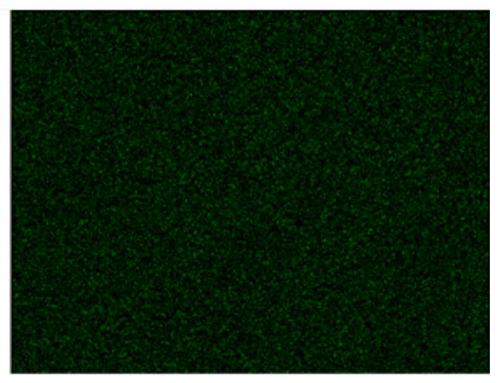

Co Ka1

Fig. 9 The elemental maps obtained from the as received Inconel 617 reveals the presence of titanium rich precipitates

Fig. 10. Figure 10 shows that the titanium rich precipitates have reduced in number. This implies that the number of micro-galvanic couples would reduce and in turn would enhance the corrosion resistance of the EB treated samples vis-à-vis the as-received Inconel material. Thus the EB treatment on account of its ability to refine the microstructure and redistribute or refine the secondary phases is causing an improvement in the corrosion resistance of the material [46-48].

Further investigations are carried out on the corroded surfaces of both as-received and electron beam melted Inconel 617. Scanning electron microscope has been employed to study the surface dissolution at higher magnifications, as shown in Fig. 11. It is observed that the surface dissolution is prominent under the corrosive environment for as-received Inconel 617, which is however low for electron beam surface melted Inconel 617. Pits are formed due to the attacks of the chloride ions at both as-received and EB treated Inconel 617 [49]. From the appearance of surface dissolution along with the pit formation, it may be concluded that the electron beam melting operation helps to mitigate the attacks of corrosive species on the surface of Inconel 617. 


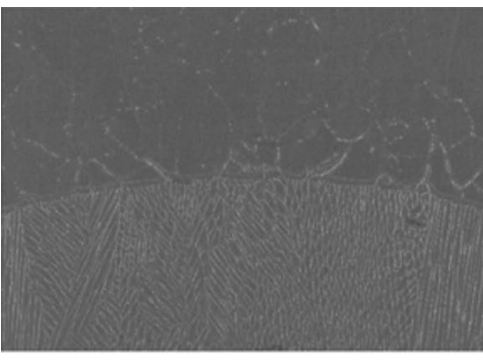

Electron Image 1

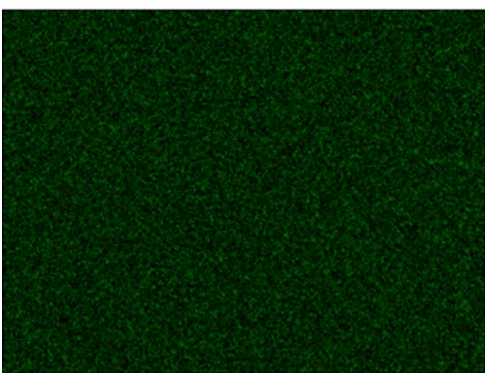

Cr Ka1

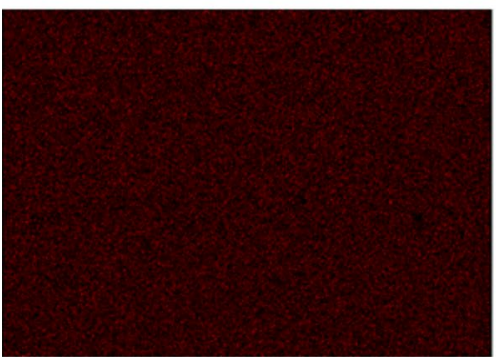

Ni Ka1

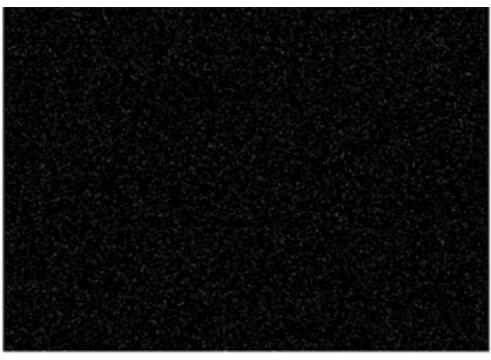

Al Ka1

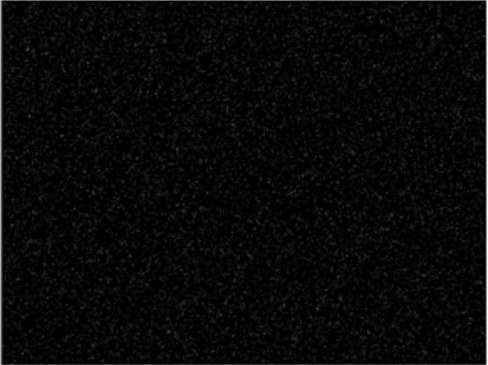

Fe Ka1

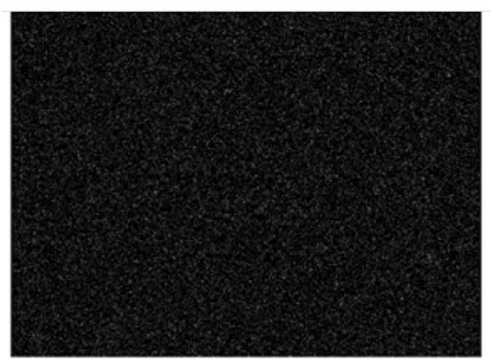

Mo La1

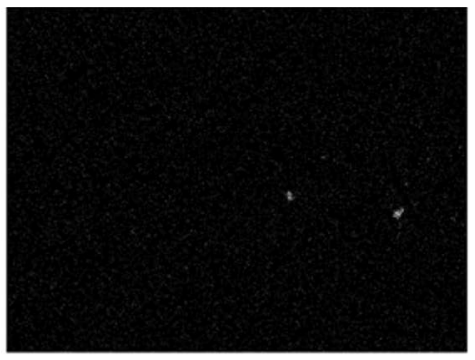

Ti Ka1

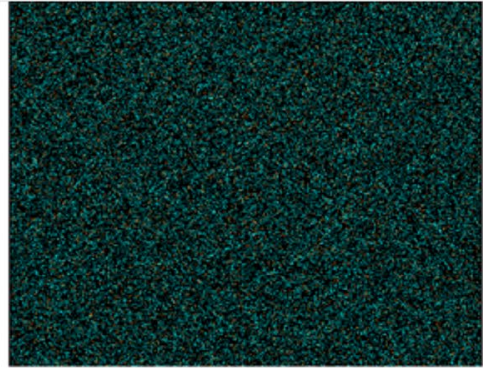

Co Ka1

Fig. 10 The elemental maps obtained from the EB treated Inconel 617 reveals evidence of the reduction of titanium rich precipitates compared to the as-received Inconel 617

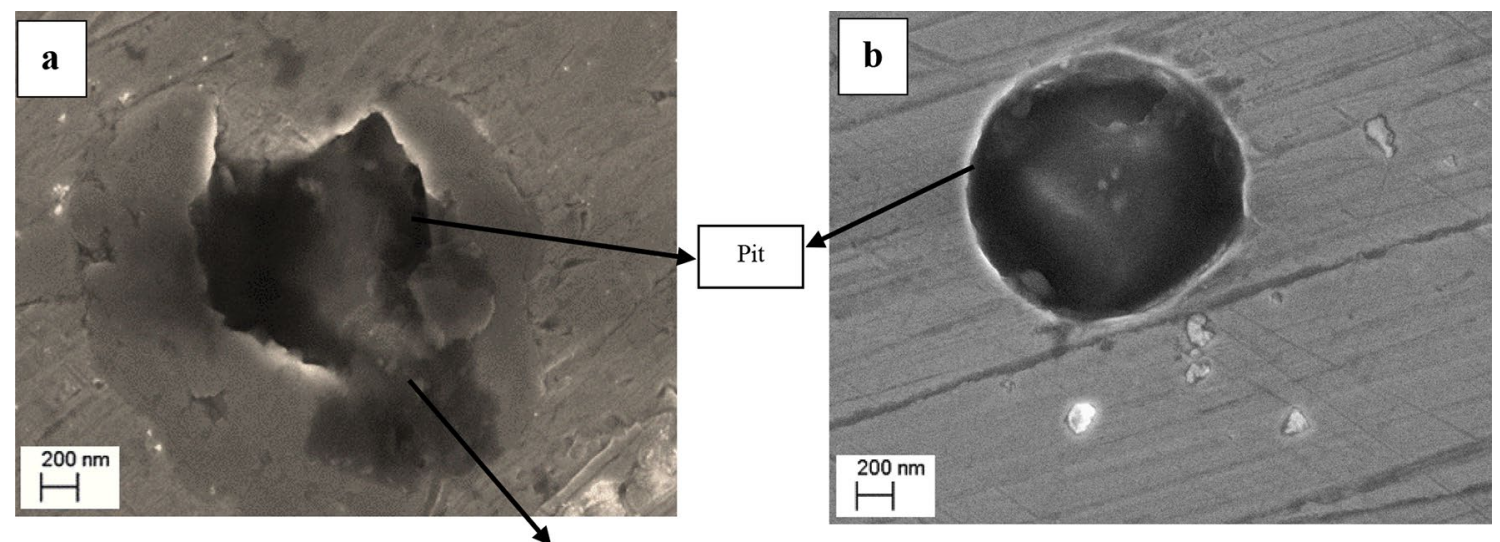

Surface dissohution

Fig. 11 Scanning electron microscopic observation on the corroded surfaces $\mathbf{a}$ as-received Inconel 617 and $\mathbf{b}$ Electron beam surface melted Inconel 617

\section{SN Applied Sciences}

A SPRINGER NATURE journal 


\section{Conclusions}

In this present study, a detailed characterization on microstructural, surface hardness and corrosion properties of EB treated Inconel 617 has been carried out. Surface melting leads to the formation of fine columnar structure at the solid-liquid interface followed by which there is presence of columnar dendritic morphology near to the surface. There is a significant improvement in microhardness following EB treatment of Inconel 617 due to the low mean free length available for dislocation motion and this is on account of the fine microstructural features in the EB treated material compared to the as-received substrate. The corrosion resistance of the EB treated surface of Inconel 617 was also found to be improved in terms of shifting in corrosion potential towards noble direction and decrease in corrosion rate, possibly because of grain refinement, microstructural homogenization and surface purification by high energy electron beam irradiation.

Acknowledgements The authors would like to thank Indian Institute of Technology Bhubaneswar and Indian Institute of Technology Kharagpur for their support and motivation toward publishing this work.

\section{Compliance with ethical standards}

Conflict of interest The authors report no conflict of interest. The authors alone are responsible for the content and writing of the article.

\section{References}

1. Allen T, Busby J, Meyer M, Petti D (2010) Materials challenges for nuclear systems. Mater Today 13(12):14-23

2. Cattant $F$, Crusset $D$, Féron $D(2008)$ Corrosion issues in nuclear industry today. Mater Today 11(10):32-37

3. El-Awadia GA, Abdel-Samada S, Elshazly Ezzat S (2016) Hot corrosion behavior of $\mathrm{Ni}$ based Inconel 617 and Inconel 738 superalloys. Appl Surf Sci 378:224-230

4. Lee H-T, Hou W-H (2012) Fine grains forming process, mechanism of fine grain formation and properties of superalloy 718 . Mater Trans JIM 53(4):716-723

5. Rahman M, Priyadarshan G, Raja KS, Nesbitt C, Misra M (2009) Characterization of high temperature deformation behavior of INCONEL 617. Mech Mater 41:261-270

6. Gertsman VY, Bruemmer SM (2001) Study of grain boundary character along intergranular stress corrosion crack paths in austenitic alloys. Acta Mater 49:1589-1598

7. Gulzar A, Akhter JI, Ahmad M, Ali G, Mahmood M, Ajmal M (2009) Microstructure evolution during surface alloying of ductile iron and austempered ductile iron by electron beam melting. Appl Surf Sci 255:8527-8532

8. Chen CH, Alstetter CJ, Rigsbee JM (1984) Laser processing of cast iron for enhanced erosion resistance. Metall Mater Trans A 15:719-728

9. Filetin T (2001) An overview of the development and application of advance materials. Croatian Welding Society, Zagreb
10. Benyounis KY, Fakron OMA, Abboud JH, Olabi AG, Hashmi MJS (2005) Surface melting of nodular cast iron by Nd-YAG laser and TIG. J Mater Process Technol 170:127-132

11. Gadag SP, Srinivasan MN, Mordike BL (1995) Effect of laser processing parameters on the structure of ductile iron. Mater Sci Eng A 196:145-151

12. Roy A, Manna I (2001) Laser surface engineering to improve wear resistance of austempered ductile iron. Mater Sci Eng A 297:85-93

13. Ahmad M, Akhter Jl, Ali G, Akhtar M, Choudhry MA (2006) Characterization of electron beam modified surface of Zircaloy-4. J Alloys Compd 426:176-179

14. Helmer $H$, Bauerei $A$, Singer RF, Körner C (2016) Grain structure evolution in Inconel 718 during selective electron beam melting. Mater Sci Eng A 668:180-187

15. Murr LE, Martinez E, Gaytan SM, Ramirez DA, Machado BI, Shindo PW, Martinez JL, Medina F, Wooten J, Ciscel D, Ackelid U, Wicker RB (2011) Microstructural architecture, microstructures, and mechanical properties for a nickel-base superalloy fabricated by electron beam melting. Metall Mater Trans A 42(11):3491-3508

16. Amato KN, Hernandez J, Murr LE, Martinez E, Gaytan SM, Shindo PW (2012) Comparison of microstructures and properties for a $\mathrm{Ni}$-base superalloy (alloy 625) fabricated by electron and laser beam melting. J Mater Sci Res 1(2):3

17. Gaytan SM, Murr LE, Medina F, Martinez E, Lopez MI, Wicker RB (2009) Advanced metal powder based manufacturing of complex components by electron beam melting. Mater Technol 24(3):181-190

18. Gong X, Anderson T, Chou K (2014) Review on powder-based electron beam additive manufacturing technology. Manuf Rev 1(2):507-515

19. Mahajan S, Pande CS, Imam MA, Rath BB (1997) Formation of annealing twins in f.c.c. crystals. Acta Mater 45(6):2633-2638

20. Meyers MA, Murr LE (1978) A model for the formation of annealing twins in FCC metals and alloys. Acta Metall 26(6):951-962

21. Pande CS, Imam MA, Rath BB (1990) Study of annealing twins in FCC metals and alloys. Metall Mater Trans A 21(11):2891-2896

22. Zhao S, Xie X, Smith GD, Patel SJ (2003) Microstructural stability and mechanical properties of a new nickel-based superalloy. Mater Sci Eng A 355(1):96-105

23. Biamino S, Penna A, Ackelid U, Sabbadini S, Tassa O, Fino P, Pavese M, Gennaro P, Badini C (2010) Electron beam melting of Ti-48Al-2Cr-2Nb alloy: microstructure and mechanical properties investigation. Intermetallics 19:776-781

24. Facchini L, Magalini E, Robotti P, Molinari A (2009) Microstructure and mechanical properties of Ti-6Al-4 V produced by electron beam melting of pre-alloyed powders. Rapid Prototyp J. 15:171-178

25. Bontha S, Klingbeil NW, Kobryn PA, Fraser HL (2009) Effects of process variables and size-scale on solidification microstructure in beam-based fabrication of bulky 3D structures. Mater Sci Eng A 513:311-318

26. Flemings Merton C (1974) Solidification processing. Metall Trans 5(10):2121-2134

27. Guo E, Phillion AB, Cai B, Shuai S, Kazantsev D, Jing T, Lee PD (2017) Dendritic evolution during coarsening of $\mathrm{Mg}-\mathrm{Zn}$ alloys via 4D synchrotron tomography. Acta Mater 123:373-382

28. Osório WR, Freire CM, Garcia A (2005) The effect of the dendritic microstructure on the corrosion resistance of $\mathrm{Zn}-\mathrm{Al}$ alloys. J Alloys Compd 397:179-191

29. Porter DA, Easterling KE, Sherif MY (2009) Phase transformations in metals and alloys, 3rd edn. CRC Press, Boca Raton

30. Ohno A (1976) The solidification of metals. Chijin Shokan Co., Ltd., Tokyo, p 144 (Book-English) 
31. Mankins WL, Hosier JC, Bassford TH (1974) Microstructure and phase of Inconel alloy 617 stability. Mater Trans 5:2579-2590

32. Taheri N, Naffakh-Moosavy H, Ghaini FM (2017) A new procedure for refurbishment of power plant Superalloy 617 by pulsed Nd:YAG laser process. J Optlastec 91:71-79

33. Cullity BD (1967) Elements of X-ray diffraction. Addison-Wesley, Manila

34. Nath S, Manna I, Ray SK, Majumdar JD (2016) Studies on nanotribological and oxidation resistance properties of yttria stabilized zirconia (YSZ), alumina $\left(\mathrm{Al}_{2} \mathrm{O}_{3}\right)$ based thin films developed by pulsed laser deposition. Ceram Int 42:7060-7071

35. Sharma P, Majumdar JD (2012) Surface characterization and mechanical properties' evaluation of boride-dispersed nickelbased coatings deposited on copper through thermal spray routes. J Therm Spray Technol 21(5):800-809

36. Willnecker R, Herlach DM, Feuerbacher B (1990) Grain refinement induced by a critical crystal growth velocity in undercooled melts. Appl Phys Lett 56:324-326

37. Mason DP, Van Aken DC (1993) The effect of microstructural scale on hardness of $\mathrm{MosSi}_{2}-\mathrm{Mo}_{5} \mathrm{Si}_{3}$ eutectics. Scripta Metall Mater 28:185-189

38. Zuo X, Zhao C, Zhang L, Wang E (2016) Influence of growth rate and magnetic field on microstructure and properties of directionally solidified Ag-Cu eutectic alloy. Materials 569:9

39. Guo GG, Tang G, Ma X, Sun M, Ozur GE (2013) Effect of high current pulsed electron beam irradiation on wear and corrosion resistance of Ti6Al4 V. Surf Coat Technol 229:140-145

40. Ralston KD, Birbilis N (2010) Effect of grain size on corrosion: a review. Corrosion 66(7):075005

41. Liu S, Wang X, Yourui T, Han X, Cui C (2019) Enhanced corrosion resistance of 5083 aluminum alloy by refining with nano-CeB6/ Al inoculant. Appl Surf Sci 484:403-408
42. Walker JC, Murray JW, Nie M, Cook RB, Clare AT (2014) The effect of large-area pulsed electron beam melting on the corrosion and microstructure of a Ti6Al4 V alloy. Appl Surf Sci 311:534-540

43. Lei MK, Dong ZH, Zhang Z, Hu YF, Zhu XP (2007) Wear and corrosion resistance of Ti6AI4V alloy irradiated by high-intensity pulsed ion beam. Surf Coat Technol 201(9):5613-5616

44. Chung M-K, Choi Y-S, Kim J-G, Kim Y-M, Lee J-C (2004) Effect of the number of ECAP pass time on the electrochemical properties of 1050 Al alloys. Mater Sci Eng A 366:282-291

45. Seri O, Furumata K (2002) Effect of Al-Fe-Si intermetallic compound phases on initiation and propagation of pitting attacks for aluminium 1100. Mater Corros 53(2):111-120

46. Zhang XD, Zou JX, Weber S, Hao SZ, Dong C, Grosdidier T (2011) Microstructure and property modifications in a near a Ti alloy induced by pulsed electron beam surface treatment. Surf Coat Technol 206(2):295-304

47. Watkins KG, McMahon MA, Steen WM (1997) Microstructure and corrosion properties of laser surface processed aluminium alloys: a review. Mater Sci Eng A 231:55-61

48. Wong TT, Liang GY (1997) Effect of laser melting treatment on the structure and corrosion behaviour of aluminium and AISi alloys. J Mater Process Technol 63:930-934

49. Basak S, Sahu KK, Sharma SK, Majumdar JD (2016) Studies on electron beam surface melting of AISI 316 stainless steel and AISI 347 stainless steel. Procedia Manuf 7:647-653

Publisher's Note Springer Nature remains neutral with regard to jurisdictional claims in published maps and institutional affiliations. 